\title{
Corporate Responsibility and Sustainable Development
}

\author{
Paolo Ricotti ${ }^{*}$
}

\begin{abstract}
Corporate responsibility marks a historical turnaround in corporate culture because it attributes to it a role in which many costs externalised by the company to society and to the planet, but in fact produced directly or indirectly by it.

A correct cultural approach and greater familiarity, particularly with the issues of manufacturing processes and products that have no impact on the environment, can make companies truly responsible and conscious of their role.

Corporate Responsibility differs from Corporate Social Responsibility. The former represents the corporate 'system' (capital, human resources, suppliers, processes, products, communication, customers, etc.), while the latter refers to the 'system' of stakeholders (the community, institutions, associations, etc.).
\end{abstract}

Keywords: Corporate Social Responsibility; Corporate Responsibility; Development; Competitiveness; Global Corporations; Global Markets

\section{Introduction}

This article considers the effects on society and on the planet of an industrial economy based on brands and mass consumption, in other words the industry that epitomises the great phenomena of the market, life styles and globalised consumption: all the other industrial and service sectors can be referred to this vision, although with the prospective of a slower structural evolution.

\section{Origins of Corporate Social Responsibility}

In recent years we have observed a new phenomenon in the field of corporate culture, which is attempting to drive the operational behaviour of management towards the achievement of broader objectives than the traditional goals of profit; in other words, those linked to other fundamental values like respect of the environment, of human dignity and of society in general.

* Planet Life Economy Foundation, President (info@plef.org) 
This cultural evolution is taking place as part of a philosophy known as 'Corporate Social Responsibility' (CSR). In other words, we are trying to supplement our traditional tangible values, which can be defined quantitatively, with other mainly intangible values that are hard to identify and to interpret, but which have come to represent the company's real values, the values that motivate the strategic and economic foundations that underpin the purchase and sale of company shares, and not necessarily those defined by financial indices or by the Stock Market.

These intangible values might be the value of the trademark, the loyalty and motivation of collaborators, consumer loyalty, respect and reputation in the local community, or credibility and trust on the part of the financial community and institutions.

What would be the value of Coca Cola or Armani, without the trademark or brand name? Probably nothing, or less than nothing, because their organisations, manufacturing plants and personnel would basically represent very costly management burdens and not real competitive advantages.

What would be the value of Sapori if, as well as taking away the brand, one were to move the company from Siena? Again, the value would be practically nothing because it would be no more than a 'me-too' product with no credible added value that is accepted by the consumer.

In large corporations this reasoning is often part of an approach to corporate strategy that is well established in their internal values and culture, imposed directly by top management (CEO): the company's 'brand policy'.

This aspect of management is the fundamental element that governs the company's competitive positioning, and it is the element that, together with other specific components (target, essential benefits, category, price level, means of expression or consumption) is able to sustain the real added value of a company or a specific product, rather than the simple service rendered or its marketing mix.

For example, the brand is actually able to represent consumers' lifestyles and profound cultural aspirations for all those who strive to be a part or be perceived to be a part of that specific community.

In fact, until the end of the last century, the focus was more on the creation of the value of individual product brands or product ranges, because they were the central element of the bond with the consumer and his loyalty. Today, the focus tends to be on the brand policy of the entire company, which is oriented not only to the consumer but also to all the stakeholders.

Stakeholders are all the parties who are involved directly or indirectly in a company's activities, and therefore not only consumers, employees and shareholders. The so-called 'brand policy' is simply a definition of the rules and strategic reasoning that every serious company defines and sets as a long-term objective in relation to competitors, to other brands and products existing in the same company and to all these stakeholders.

In other words the notion of CSR has a very precise origin within the strategic principles that many large companies adopted several years ago, and now wish to transfer as the culture of correct management to a vaster number of companies.

However, things are changing in the large corporations. Until a few years ago, brand policy was an internal issue that was not declared publicly outside the company, because awareness of the company and its image were based on the force 
and recognition of individual product brands. Today on the other hand, the weight and strategic importance of the company is being transferred from product brands to the company brand, in other words, to the company as a whole and its 'corporate policy'. In my opinion this evolution has become necessary for two fundamental reasons:

- the central role of the large retail, which has stolen from the company the notion of brand loyalty, supplementing it with the notion of store loyalty. Trade also directly governs other fundamental levers of the marketing-mix that were once controlled entirely by industry and are now only negotiated with the retail trade: the retail price, packaging, format and shelf policy, promotional materials for the point of sale and promotions. In this context the company, which often loses in negotiations with the retail that monopolises its direct link with the consumer, tries to play its role, establishing its credibility at a higher level in relation to both the retail trade and the consumer. The notion of 'consumer' now acquires a broader connotation, no longer that of user of a specific product, but that of the 'citizen' who knows how to value the products, but above all the companies that manufacture and sell them, conscious of his active role in the society that he lives in and belongs to. And it is no coincidence that the level of intervention and negotiation is higher, centralising both commercial and manufacturing decisions, gradually taking them away from single markets, and calling into question the entire company, its history and its fundamental values;

- the impact of the growing globalisation of the markets, which can no longer ignore the existence of different parameters and paradigms, country by country, and therefore a different connotation of the company, depending on the country it is seen from. Globalisation is therefore an advantage for large corporations, but it also sets limits, which derive from its conduct and image that must always be the same, all over the world. And because consumer markets are different in terms of products and brands (multinationals occasionally adopt a different product brand policy to reflect the evolution of a particular market, which is often the result of local acquisitions of companies that managed local brands that were much stronger and better known than their international counterparts), the only firm, exclusive reference for all its publics must be the company's 'brand policy'.

\section{Corporate Social Responsibility in Europe}

These issues prompt endless debate and schools of thought. However, we must recognise that some excellent companies have been building up a corporate culture for years, due both to an evolutionary thrust of their own (historical values and missions), and to the fact that on July 18, 2001, the European Union published a green book defining a European framework to promote the Social Responsibility of companies. This text indicated which concrete cultural references should be adopted and, above all, clarified that socially responsible companies must pursue not only goals of pure profit but also, and simultaneously, goals focussed on society and the environment: the 'triple bottom line'. 
It is a vision that endorses the fundamental message of the strategy of sustainable development adopted by the Gothenburg European Council in June 2001, which established that, in the long term, economic growth, social cohesion and the protection of the environment must go hand in hand. In Italy, CSR parameters were defined by the Ministry of Welfare in 2003, and presented at a conference in Venice on November 14 last year.

These parameters were interpreted from a typically Italian perspective, paying particular attention to the domestic manufacturers and therefore to SMEs (Small and Medium Enterprises). They incorporated the notion of CSR-SC, in which Social Commitment refers to companies' active participation in government welfare schemes at a national or local level, on a voluntary basis.

Even the Dow Jones Sustainability Index (DJSI) attributes precise indices and parameters to the classification of ethical and responsible companies whose operations comply with the general principles of CSR. It has already classified 314 responsible companies, of which 65 are in the USA, 71 in the UK, 35 in Japan, 23 in Germany and only two (Unicredit and Monte dei Paschi di Siena) in Italy.

The general principles of CSR are currently only widespread in a small number of companies, and Italy is only at the beginning. These principles are not yet used in full by companies. For the time being, they focus on certain variables that are primarily linked to the internal management of human resources or to the company's Social Commitment, i.e. its link with the general public, patronage and philanthropy. We are still a long way from a real assumption of responsibility regarding the impact of manufacturing activities (processes, products, waste) on the vitality of the environment and therefore on the health and quality of life of its inhabitants.

In manufacturing companies, adapting to the general principles of CSR on this particular point seems more complex, because it is technically difficult and apparently more costly to restructure industrial processes. This discourages the good intentions of businessmen and managers.

In fact, it has been amply demonstrated with concrete examples ${ }^{1}$ that this perception is not correct from either the viewpoint of available technologies or that of economic financial returns. In fact, it has been amply demonstrated that a comprehensive CSR approach, linked to the protection of the environment, gives a company considerable competitive advantages and the capacity to develop its market and added value ${ }^{2}$.

An investigation of company balance sheets and sustainability undertaken in Italy $^{3}$ by the Foundation that I chair (Planet Life Economy Foundation: www.plef.org), revealed what I have already mentioned, i.e. that today companies tend increasingly to comply with the elements of CSR that regard respect of human resources $(89 \%)$, patronage and philanthropy $(86 \%)$, and management of waste and emissions (54\%), but not yet management of processes/products from the perspective of environmental compatibility (27\%).

This appears in sharp contrast with the expectations of the public, who would prefer to focus on the elements linked to the environment (24\%) rather than those of society (15\%), human resources (14\%) and support to non-profit associations (3\%). $69 \%$ of the population feel that large companies are not sufficiently active in constructing a better society for everyone, with a significant decrease in respect for 
their executives $(-40 \%)^{4}$, confirming the urgency of the evolution of corporate culture that is referred to in CSR programmes.

The application of CSR in Italy still focuses in particular on a greater commitment by the company to the demands of society, misinterpreting the original significance of the term 'social', which on the contrary means encouraging a corporate commitment even to issues of environmental compatibility.

\section{Corporate Social Responsibility and Corporate Responsibility}

To settle the matter, it would be more correct to use a more absolute term for a company's responsibilities, focusing the company's commitment on a more precise responsibility: Corporate Responsibility (CR).

Corporate responsibility differs from Corporate Social Responsibility to the extent that the former represents the corporate 'system' (capital, human resources, suppliers, processes, products, communication, customers, etc.) in relation to its own direct responsibilities, while the latter refers to the 'system' of stakeholders, and therefore to the company's own responsibilities shared with other parties (the community, institutions, associations, etc.).

This approach finds logical consistency in the fact that the company is the primary subject which can contribute, more than any other, to the creation of the well-being and quality of life of any society, because the added value that makes significant any consideration of values and material wealth in our civilisation is created in the company.

There is often confusion about the idea of 'profit', which is interpreted as a company's final goal, forgetting that profit is only the bottom line in the company accounts, and that above this line there are a great many specific cost items related to the other factors of added value creation, which represent and explain the true nature and primary role of a given company.

In other words, the degree of well-being generated by a company is measured by its ability to create overall added value: this added value is what is then used to generate and sustain employment (salaries), to purchase raw materials, semifinished products, consumer goods, expertise and miscellaneous services, to invest in research and communications, to amortise structural tangible and intangible capital spending, to repay the capital invested and working capital, and so on.

Part of this same profit, and other items that imply tax liability (for example VAT, IRPEF, the taxes paid by the company, by its employees, and by its suppliers on the services rendered to that specific company, etc.) are what determine the basis of the added value for public sector employment and other outsourced cost items managed by other public and private entities (government, public authorities, healthcare, education, refuse, territory and environment, etc.).

And finally, the notion of profit also incorporates the repayment of the capital invested by shareholders, which is often employed to create further opportunities to create value (inside and outside the company).

To conclude, the greater the added value created by the company, the greater the well-being and quality of life created in that specific territorial area, 'chain' or industrial district. 
If there is no added value there is no employment, research, training, communication or development by the company; if there is no added value for the company there can be no welfare, healthcare, education, infrastructure, defence or society: the failure of the 'socialist' economic model to support the needs of society as a whole.

But if overall wellbeing is 'economically' determined by the company's ability to generate added value, this implies that this added value should be sufficient to cover all the costs that a given company generates and needs: the greater the costs and the overall needs, the greater the added value necessary.

So we cannot treat the mechanism by which added value is generated as completely separate from the way the needs of society are created and managed, but must maintain a uniform and 'systemic' vision of the entire process, clarifying the roles and responsibilities.

The evolution of a given society, its growth and its decline are part of a virtuous circle, which controls the harmonious evolution between the value creation generated by the general system of companies and the correct 'social and environmental' use of tax liabilities. And if this harmony is disregarded by one of the three parties (company, society and planet), the whole system is certain to collapse.

This is why the notion of CR is culturally and structurally so significant, because it tries to create order in these notions of stable long-term equilibrium, but it is equally certain that if the notion of CR is confused with that of CSR, i.e. limited to a role of greater social awareness on the part of the company, on a voluntary basis, possibly undertaking some public relations activity with a little patronage, some good 'Cause Related Marketing' (CRM) promotional programme, some form of certification, an 'artistic' and technically perfect social and environmental report, etc., all this is totally insufficient. Our companies must be aware that they are responsible first and foremost for the harmony of the entire system, and that they really must undertake to improve the well-being and overall quality of life, taking on a real 'Corporate Responsibility' (CR), and not on a voluntary basis.

This corporate responsibility must take into account the fundamental role played by communications and training in current civil development: two fundamental levers that are necessary to implement real changes in lifestyles and professional and social conscience.

\section{Corporate Responsibility and Compatibility}

The company, the market economy and the creation of added value is the hard core around which the entire reasoning of the development of a given society revolves. It is no coincidence that the development of our civilisations is based on the idea of the 'market', a place to meet and to exchange services, goods, raw materials, semi-finished goods and finished manufacts, labour and more besides. Nor is it a coincidence that our civilisations and towns have developed around this notion of the 'marketplace', the place and basic reference for anyone who wishes to meet, to create culture, to do business, to innovate or to follow religious rites (temples, churches, etc.). 
And it is not a coincidence that the birth and death of certain civilisations have always depended on their ability to attract wealth, population flows and religions to those territories and to those towns, or on the contrary, to lose them and be conquered by them.

But those marketplaces and those towns have survived because of aspects linked to the availability of the natural capital ${ }^{5}$ (water, sun, air, live earth) that exists in that place or has been transferred there.

And if even one of these variables ran out (water, for example), that civilisation died or moved elsewhere. In other words, a company and society live and develop if they can take root in a part of the planet that is fertile and alive: if part of the planet is devitalised or its natural resources run out, companies can no longer produce, added value is not created and society dies.

The health of men or other living species is conditioned by the quality of the biological life of a given territory: the more that part of the planet is dead, poisoned or simply devitalised, that territory will no longer be inhabitable, because it is unliveable.

In recent decades there has been a development of civilisations that have been able to get round certain aspects related to the harmony of the vital cycles, using certain strategic natural resources without restraint and practically free of charge, but these remain scarce and unrepeatable (oil, water, etc.), or a stable biological balance (seasons, structure of the biosphere, ecosystems, etc.).

We have therefore artificially and unnaturally got round the decline of the territory, with technological artifice and remedies that will not be sustainable in the long term. Correct corporate responsibility cannot fail to notice this evolution, and cannot but realise that the primary need of all living beings is first and foremost its existence: the capacity to be able to live, the possibility to be able to live well, in good health, making the most of the asset that has made life possible and rich: the planet and its natural products. The more precarious these primary needs are made, the greater the demand for them and the struggle to enjoy them and appropriate them.

Today we struggle and fight to appropriate the last drops of oil, tomorrow we will fight to appropriate the last drops of water and the last healthy, living, unpolluted environments (even if the air and the seasons are inexorably being modified and deteriorating all over the planet).

Nor can we hide behind the logic of individual egoism - by which only one part of the population survives well and comfortably, and the other dies - because this means burying our heads in the sand, intervening too late, making a useless defence of ourselves, and refusing to understand or to see the true causes of this decline, which will nonetheless, involve us sooner or later ${ }^{6}$.

On the other hand, it is not only a problem of 'sustainability', in the sense that all our reasoning cannot be bought down to the environment and society in general, but must be extended to the constraint of individual needs.

Society is made up of living beings who express desires, passions and emotions, and their life model regards their degree of civil evolution, which is not necessarily linked to the level of maturity of the community they belong to. The greater their level of development, the greater their aspirational and immaterial needs compared to their primary material needs. 
Our aspirational needs incorporate our pleasure in goods linked to emotions, and products and services that are rich with symbolic as well as sensory elements and values (e.g. design, fashion, wine, perfume, lifestyle products, personal computers, cable TV, cell phones, etc.). Our immaterial needs embrace everything that refers to the accumulation of culture and tradition by a given person (art, entertainment, amusement, sport, tourism, spirituality, family culture, etc.).

So while the principles of sustainability tend to evaluate problems through the filter of the capacity for the long-term survival of the populations of the planet and the planet itself, the principles of 'compatibility' extend these aspects to a notion of collective well-being and quality of life generally, without useless sacrifice or cultural frustrations. Although they embrace the principles of 'sustainable development' in full, the principles of 'compatibility' put the general notions into practice through the filter of market logics, taking into account both the structural and economic needs of companies and those of individuals seen as exploiters of goods and individual material and immaterial services, satisfying their expectations, desires, pleasures and dreams in full. The 'compatible' economy is sustainable development seen from the perspective in terms of market practicability.

The great planetary scenarios, universal philosophies and ideals will never be understood or accepted by many companies or by the public if they do not pragmatically embrace the simple logics of everyday life. If it is to become reality and not remain an abstract notion, sustainable development must become an integral part of the market and the company, all through the manufacturingdistribution-communication-consumption-recycling chain.

Correct corporate responsibility is addressed simultaneously at developing one's own added value and its competitive advantage, but is always fully compatible with an improvement in the quality of life of society in general and of collective wellbeing.

\section{Corporate Responsibility and Critical Factors}

The firm is not the only responsible in this process of evolution (governments, institutions, society and religions all play an undeniably important role), but it is important to underline that it is mainly in the company that the conditions are established for a real and feasible change to economic and social paradigms.

The rules, principles and recommendations defined by organisations and institutions outside the company are, and remain, valid and very useful if they are correctly addressed and controlled but, if something is really to change in the end, we have to rely on the real behaviour of companies and the use of the added value that is generated.

Many of the historical paradigms related to corporate culture and management have already changed or at least been identified. CSR, and the governments that support it, identifies some fundamental paradigms (the triple bottom line). The UN Global Compact identifies others that are synergetic ${ }^{7}$. In spite of this, there are still a number of fundamental issues that are critical or even obsolete for a correct evolution of the company and its universal responsibilities. I would like to mention a few that I consider priorities: the energy question, population growth, the 'low price syndrome' and finally the idea of growth and the calculation of GDP. 
This is not the place to examine these issues in depth or to propose exhaustive solutions, but it is probably worth making some brief comments.

\subsection{Energy}

Solar energy (which in turn implies and induces the creation of other renewable forms of energy: photovoltaic, wind, tides, waves, hydroelectric, etc.) is the only type of energy that can create harmony and wealth among people, because it is the only democratic and compatible source of energy. It is available locally without centralised infrastructure, never-ending, technologically and economically accessible to all the people on the planet and non-polluting. Any other type of energy (oil, coal, biomass, natural gas, nuclear, human, etc.) ${ }^{8}$ is exactly the opposite in every way of the implications listed above, and is the main cause of the everlasting hostilities of our civilisation?

The current amount of fossil fuel energy used annually at a global level represents an infinitely ridiculous fraction $(1: 14000 \text { - one to fourteen thousand })^{10}$ of the solar energy available every year. Greater attention to this type of renewable energy, convinced technological research for domestic and industrial applications, greater communication and information to all end users and a systematic approach when evaluating overall costs, would generate both economies of scale and real applications that could make this type of energy much more accessible and competitive for everyone.

In the last century there have been all sorts of efforts to invest in research and to optimise the use of other polluting and undemocratic sources of energy, and very little has been done to make available to the people of world the only infinite, clean source that is available to each of us right in our own homes: solar energy.

\subsection{Population}

The population of the planet cannot grow out of all proportion, or it will result in the collapse not only of the economy and of society, but of the planet itself. Since populations also tend to live longer than in the past, it is impossible to imagine, or project into the long term, the continuous growth of the population which, like proliferating cancer cells, would eventually kill itself, after having devastated the surface and blocked the functions of all its vital centres.

It is not a problem of religious principles, nor a social problem, but simply a problem of the survival of the human race, unless we wish to arrive at a total collapse and then to observe the disaster from the perspective of the few beings to survive the collapse ${ }^{11}$, in order to learn from it. We have to implement a strong, decisive birth control plan in a context of harmonious relations between the peoples of the world.

This is an issue for our supranational institutions and religions, and we need population control conventions on a par with the Kyoto convention. But it is also the responsibility of companies that have not yet modified one of the fundamental paradigms of their strategic approach: the growth and development of consumption. The first parameter for the strategic organisation of a multinational company is that of increasing its consumer base, paying particular attention to the birth rate and development in developing countries where the population is expanding. 
Correct corporate responsibility should declare and clarify that the perspective evolution of that particular company rests on factors that exclude the promotion and development of births, but refer, on the contrary, to a situation of static population.

\subsection{Low Price Syndrome}

The 'low price' syndrome is causing victims among numerous responsible companies, creating terrible paradigms in terms of management practices and habits, favouring short-term speculation - which often rewards irresponsible companies - and clouding the logic of the competitiveness of entire economic systems.

This syndrome has forcibly entered the industrial and commercial logics of nearly all manufacturing, retail and service companies, sacrificing the protection and defence of the limited purchasing power of much of the public.

This is not the place to discuss the origin of the problem, which is often linked to irresponsible speculation, but we should analyse what this syndrome entails in the light of the comments made above regarding the equation: more added value created $=$ more well-being for everyone.

I believe that we should do more in this context - which brings into play the evolutionary and strategic vision of entire economic systems. We should examine this chain of value and introduce rules and constraints that can create an intrinsic homogeneity of the processes and products: not just a free market, but a responsible and 'compatible' free market.

The issue is once again the prime responsibility of our institutions and governments, but it is also clearly the responsibility of companies: to create a market they must focus more on quality and the creation of collective well-being, and not only on low prices. They have to create a 'culture of value' and transmit it correctly and comprehensibly to the public for them to decide. We need to demolish the 'low-price syndrome', transforming it into a notion of minimum possible price for the same compatible value.

\subsection{Gross Domestic Product}

We need to do something to modify the logics and calculations that define certain basic measurements and indices, which in turn influence the decisions of governments and the financial world. In particular the notion of the GDP of industrialised countries as a monetary parameter that measures the 'growth' of a particular nation must evolve.

I think this parameter is obsolete, both because the notion of 'growth' is unsustainable in the long term and because today it no longer measures the 'wellbeing' of a population but its 'malaise'. We only have to see how GDP moves (increasing or decreasing?) in the case of some phenomena that we can all see: wars, ecological disasters, the devastating effects of a hurricane or a flood, increased spending on individual security, increased waste, its recycling and elimination, rising pollution, toxic waste and greenhouse gases, spending on healthcare to fight cancer, leukaemia, allergies, epidemics, and so on.

In all these cases of obvious malaise for a given society, GDP increases wildly, apparently measuring wealth but in reality measuring serious and dangerous 
malfunctions. In a compatible market economy, these indices should change, to define which monetary values create real added value and well-being for society and the planet (to be added), and which on the other hand are destined to repair the damage done (to be subtracted).

We should also do much more to ensure that the financial system drastically revises its principles to evaluate the competitive quality and 'good health' of our companies, rewarding those that reveal a 'long' and 'compatible' chain of value, and real determination to manage corporate development by the correct use of the resources that they have accumulated over the years, giving more credit to companies that create income and 'local' well-being and less to the 'smart' ones that do not want to risk or that implement speculative short-term policies.

Even if the Dow Jones Sustainability Index already tries to monitor and value the companies that implement a CSR policy in some way, I think we should do more, both by revising the parameters in a perspective of Compatible $\mathrm{CR}$, and by modifying the current criteria for reliability defined in the Basel 2 agreement $^{12}$.

\section{Corporate Responsibility, Development and Competitiveness}

Current market paradigms, the questionable logic of low prices, the shortsightedness of many governments and the lack of awareness of the public certainly do not foster the development of a strong and correct corporate responsibility.

We have already stated that because other institutions cannot modify society on their own, it is a company's responsibility to lead the process of change. The company itself must understand its true role in society, and must understand that a fully responsible approach is in everyone's interest, but above all will help its own need for development, the creation of added value and overall profitability.

In the previous chapters we showed that the public judges companies that move in the direction of correct CSR positively, and we also pointed out the critical factors of a longer wait. We are therefore faced with a significant evolution of awareness on the part of demand that precedes the creation of new, important markets.

We have already mentioned the other critical factors that can prompt companies to adopt real, complete corporate responsibility. It is now necessary to appeal to the real evolutionary changes, demonstrating the company's new attitude with facts and figures and communicating them correctly to the general public, the financial world and the institutions. Once again we must underline that the quality, correctness and execution of communications play a critical role in the entire evolutionary process, and this increases the sensitivity of the individual and orients his final preferences at the moment of consumption. Success, an increase in volumes sold, an increase in added value, and a new and lasting competitive advantage are concrete and certain rewards for the company that embraces corporate responsibility.

This is not the place to analyse in detail all the advantages that a company can accumulate by exploiting these issues, both because there is not sufficient space, and because every company is different and must therefore be evaluated case by case. However, it is worth mentioning a few general advantages (regarding the field of mass consumption as we said):

- $\quad$ better agreement of the individual and therefore loyalty to consumption ${ }^{13}$; 
- the individual's readiness to pay a higher price for correct, compatible products $^{14}$

- a more favourable attitude on the part of the financial institutions ${ }^{15}$;

- greater productivity and loyalty from collaborators ${ }^{16}$;

- agreement and privileged choice by large retailers;

- extended retail market;

- agreement and support from consumer and environmental associations;

- agreement and free support from the mass media;

- agreement and support from the institutions;

- $\quad$ simplification and reduction of marketing costs (marketing mix) ${ }^{17}$;

- lowering of entrance barriers ${ }^{18}$;

- greater respect of oneself and the members of one's family for those who make choices and decisions for the company.

Firms with strong corporate responsibility can benefit from important competitive advantages that allow them to grow and develop, regardless of market trends and to the detriment of 'irresponsible' companies.

Of course large companies can benefit from more competitive advantage even on the basis of a greater territorial spread and a comprehensive, competent professional approach. But because these companies are those with the greatest structural rigidity towards change, and they suffer from the 'centralisation' syndrome, this provides a natural potential even for medium/small local companies that know how to move with vision and determination, drawing if necessary on existing external skills.

Pragmatically, the competition and added value can be boosted by analysing and modifying the individual elements of the chain of value of individual companies, observing them and developing them gradually over time, according to the logics of correct compatibility. On the other hand, a company that decides to adopt the principles of compatibility does not even have to take significant risks if it tackles the problem by observing it from the perspective of a small part of business, focusing on it, developing it and testing the results.

The market is well-disposed to accept this type of product and the company is able to grasp these significant opportunities (production, distribution, communication): not only market segmentation, but a lasting and never-ending upgrading of the market.

\section{Conclusions}

CR marks a historical turnaround in corporate culture because it attributes to it a role in which many costs externalised by the company to society and to the planet, but in fact produced directly or indirectly by it, are charged to the income statement, determining new objectives to pursue, to manage and to communicate (the triple bottom line: profit, environment, society).

This turnaround is not fully understood right now by companies that are moving in a direction that diverges from the public's expectations. A correct cultural approach and greater familiarity, particularly with the issues of manufacturing 
processes and products that have no impact on the environment, can make companies truly responsible and conscious of their role.

It is not an intellectual responsibility but a tangible responsibility, because the entire history of the evolution of people and civilisations is based on the notion of added value created by business and redistributed throughout society, just as it is certain that only business is able to fully satisfy the expectations and needs (material, aspirational and even immaterial) of the public, even taken individually.

This added value must be protected and increased to create significant competitive advantage, but also to create real awareness and responsibility of the company's role in relation to society and the institutions.

We therefore need full understanding of corporate responsibility, in which the company becomes the proactive subject for a complete review of the paradigms of consumption and the market, in which all the complex cycles, processes and systems linked to the economy can become totally compatible with the expectations of the public, society and the planet, in an endless evolutionary vision.

\section{Notes}

${ }^{1}$ Cf. Hawken, Lovins, Capitalismo Naturale, Edizioni Ambiente, 1999.

${ }^{2}$ We refer you to the DJSI graph which compares the average trend of the Dow Jones general index with that of the companies analysed by the DJSI: the graph shows that the companies in the DJSI have an average trend above $38 \%$.

3 We refer you to the PLEF analysis of Company and Environmental Reports - Dec. 2003, which is available from the site www.plef.org.

${ }^{4}$ We refer you to the Eurisko CSR Monitor 2003 research (25 countries).

${ }^{5}$ Cf. Hawken, Lovins, Natural Capitalism, 1999.

${ }^{6}$ The causes of the decline are described in the study conducted in 1972 by MIT (USA) on behalf of the Club of Rome, and published in 1972 with the title: The Limits to Growth. This Report identifies the problem to solve for the vitality of our companies and the planet in two key factors: the industrial economy of the last century and population development.

7 See Symphonya Emerging Issue in Management Issue 2 - 2002. Global Compact is a UN programme approved by Kofi Annan in 2000 which established 9 basic principles for the correct conduction of the company:

a. to support and respect the protection of internationally proclaimed human rights within the company's sphere of influence;

b. to make sure that they are not complicit in human rights abuses;

c. to uphold freedom of association to workers and the effective recognition of the right to collective negotiation;

d. the elimination of all forms of forced and compulsory labour;

e. the effective abolition of child labour;

f. the elimination of discrimination in respect of employment and occupation;

g. to support a precautionary approach to environmental challenges;

h. to encourage initiatives to promote greater environmental responsibility;

i. to encourage the development and dissemination of environmentally-friendly technologies. Thanks to direct contact with Mr. Anton Stadler, Senior Advisor of United Nation Global Compact, we have learned that a tenth principle addressing the phenomenon of 'corruption' is being finalised.

${ }^{8}$ Cf. Georgescu-Roegen, Energia e miti economici, Bollati Boringhieri, 1998.

${ }^{9}$ Cf. Rifkin, The Hydrogen Economy, 2002. 
${ }^{10}$ Cf. Lovins, Hawken, Natural Capitalism, 1999, p. 223.

${ }^{11}$ Paul Hawken, The Ecology of Commerce, Harper Business Collins 1993, p. 25.

The experiment of the island of St. Matthew, performed from 1944 to 1966, on a population of reindeer left free to multiply in a circumscribed territory showed that, after the exponential growth of the initial population, there was a sudden collapse caused by the sudden lack of environmental resources. This triggered both the onset of degenerative diseases and the death of the population: out of an initial herd of 29 reindeer, which grew to 6000, before the system collapsed suddenly in a cycle of just 3 years, only 42 still survived at the end.

12 The Basel 2 agreement is named after the city where the Bank for International Settlements (BIS) is located, the Institute that has created a Committee to regulate the financial statements of banks. Today the BIS draws together the central banks of 55 countries, including Italy, and employs 526 people from 44 countries. During the crisis of the late 1960s, the BIS played an important role in designing the international Banking Supervision infrastructure. This effort produced the agreements on banking capital of 1988 known as the Basel Agreement and its review begun in 2001, known as Basel 2.

Basel 2 sets out a system of rules based on three pillars around which the parameters for the capitalisation of banks are defined:

a) Equity requirements

b) Control of the Central Banks

c) Discipline and Transparency of the Markets.

Although the launch date was set for January 1, 2007, the complexity of the aspects listed above actually accelerated the application of many of the new parameters.

The Banks therefore created Internal rating systems, modifying the programmes for the reclassification of company accounts, in order to indicate the probability of insolvency of the company, and also considering an estimated expected loss. These changes overlapped with the introduction of the new IAS International Accounting Standards, which affect the evaluation of intangible items in particular. The application of Basel 2 implies an alarm bell for SMEs in Italy, which generally post lower capitalisation than the average for EU or North American companies. The parameters considered until now primarily regarded Stockholders' Equity, profitability, indebtedness and the general sector they belong to. In a logic of full CR and Compatible Economics these parameters must be backed up by others designed to improve the evaluation of the companies that have as little negative impact as possible on the life on the planet and on collective quality and well-being, such as:

- Territorial pollution, emissions, purification;

- Use of renewable energy, energy efficiency and efficient use of scarce resources;

- Quality and impact on health and the environment of the raw and other materials used;

- Illicit work, child labour, industrial health and safety, etc.;

- Ratio between Added Value and Sales (maximisation of Added Value created);

- Investment in activities related to social or environmental wellbeing;

- Certification and 'compatible' internal rules.

All these indices could lead to a very different evaluation of companies, rewarding those that are really responsible and correct, and punishing those which, thanks to harmful short-term policies that support their own inability to compete, can do irrecoverable harm to the health of the individual and the life of the planet [Roberto De Cardona - AD RaboBank - for PLEF- ].

${ }^{13} 29 \%$ of the public has already rewarded the companies responsible (by choosing their products or services), and $40 \%$ has punished them (Eurisko - CSR Monitor 2003).

${ }^{14} 85 \%$ of the population is prepared to pay $10 \%$ more for compatible products (Eurisko - CSR Monitor 2003).

${ }^{15} 61 \%$ of financial institutes would like to promote the inclusion of the shares of a responsible company in their financial portfolios (Eurisko - CSR Monitor 2003).

${ }^{16} 87 \%$ of collaborators is more loyal and faithful to a responsible company (Eurisko - CSR Monitor 2003).

${ }^{17}$ The issue is complex and should be analysed case by case. However it is easy to imagine that, having clearly identified the specific competitive advantages deriving from responsible behaviour 
on the part of the company, it will be possible to concentrate capital spending, making it more effective, eliminating dispersion and the 'effort' that would otherwise be necessary. It is also certain that spending on advertising can be significantly reduced, with the same impact, by exploiting word of mouth and the support of consumer and environmental associations.

${ }^{18}$ Modifying the paradigm of the market and its competitive logics attenuates the structural 'blocks' of competitors that put up 'barriers', opening up competition on new foundations. 